\title{
Avaliação de cultivares e híbridos de bananeira em quatro ciclos de produção(1)
}

\author{
Sebastião de Oliveira e Silva(2), José Cláudio de Oliveira Flores ${ }^{(2)}$ e Francisco Pinheiro Lima Neto(2)
}

Resumo - Híbridos superiores de bananeira com alta produtividade, frutos vistosos e resistência a doenças estão sendo gerados no programa de melhoramento genético da Embrapa-Centro Nacional de Pesquisa de Mandioca e Fruticultura Tropical. Este trabalho objetivou avaliar alguns desses genótipos em quatro ciclos de produção, visando sua recomendação aos agricultores. O experimento foi realizado em delineamento inteiramente casualizado, com 18 repetições, em Cruz das Almas, BA. Avaliaram-se as cultivares Grande-Naine, Nanica, Nam, Thap Maeo, Mysore, Caipira, Prata-Comum, Pacovan e Prata-Anã e os híbridos Pioneira, PA03-22, FHIA-18, PV03-76, PV03-44 e JV03-15. Analisaram-se os caracteres altura da planta, diâmetro do pseudocaule, peso do cacho, número de frutos, comprimento do fruto e ciclo. Ao longo dos ciclos, a 'Nanica' apresentou o menor porte, enquanto a 'Prata-Anã' se destacou no diâmetro do pseudocaule, seguida pela 'Prata-Comum' e pelo JV03-15. A 'Thap Maeo' sobressaiu-se no peso do cacho e no número de frutos, seguida pelo FHIA-18, no primeiro caráter, e pela 'Mysore', pela 'Caipira' e pelo FHIA-18, no segundo caráter. A 'Grande-Naine' e a 'Nanica' apresentaram o maior comprimento do fruto, enquanto o FHIA-18 e o PA03-22 destacaram-se na precocidade. A 'Thap Maeo' tem potencial para substituir a 'Mysore' e os híbridos avaliados apresentam qualidade para vir a ser recomendados aos agricultores.

Termos para indexação: $M u s a$, triploidia, tetraploidia, característica agronômica.

\section{Evaluation of banana cultivars and hybrids in four production cycles}

\begin{abstract}
New productive banana hybrids, presenting good fruits and disease resistant, have been generated at Embrapa-Centro Nacional de Pesquisa de Mandioca e Fruticultura Tropical. The objective of this work was to evaluate some of these genotypes in four production cycles, to recommend them to the farmers. The experiment was carried out in the completely randomized design with 18 replications in Cruz das Almas, BA, Brazil. The genotypes evaluated were the varieties Grande-Naine, Nanica, Nam, Thap Maeo, Mysore, Caipira, Prata-Comum, Pacovan and Prata-Anã and the hybrids Pioneira, PA03-22, FHIA-18, PV03-76, PV03-44 and JV03-15. The characteristics analyzed were plant height, pseudostem diameter, bunch weight, number of fruits, fruit length and cycle. Along the cycles, 'Nanica' presented the smallest plant height, while 'Prata-Anã' stood out in the pseudostem diameter, followed by 'Prata-Comum' and JV03-15. 'Thap Maeo' stood out in the bunch weight and in the number of fruits, followed by FHIA-18, in the first character, and by 'Mysore', 'Caipira' and FHIA-18, in the second. 'Grande-Naine' and 'Nanica' presented the largest fruit length, while FHIA-18 and PA03-22 stood out in the precocity. It was concluded that 'Thap Maeo' has potential to substitute 'Mysore', and the hybrids evaluated present quality to be recommended to the farmers.
\end{abstract}

Index terms: Musa, triploidy, tetraploidy, agronomic characters.

\section{Introdução}

A bananicultura possui grande importância econômica e social. A bananeira é cultivada numa exten-

\footnotetext{
(1) Aceito para publicação em 29 de abril de 2002.

(2) Embrapa-Centro Nacional de Pesquisa de Mandioca e Fruticultura Tropical, Caixa Postal 007, CEP 44380-000 Cruz das Almas, BA. E-mail: ssilva@cnpmf.embrapa.br, zeclaudio@yahoo.com.br, flima@cnpmf.embrapa.br
}

sa região tropical em todo o mundo, geralmente por pequenos agricultores. O Brasil é o terceiro produtor mundial, com aproximadamente 5,5 milhões de toneladas, numa área de 521 mil hectares, com rendimento de 10,55 t/ha (FAO, 2002).

As cultivares mais difundidas atualmente no País são: Maçã, Mysore, tipo Prata (Prata, Pacovan e Prata-Anã), subgrupo Terra (Terra e D’Angola) e subgrupo Cavendish (Nanica, Nanicão e Grande-Naine). A banana 'Maçã' é a preferida pela 
maioria dos consumidores em razão de seu paladar, obtendo maiores preços no mercado. Todavia, devido a sua alta suscetibilidade ao mal-do-panamá, está sendo dizimada de norte a sul do País (Silva et al., 1999a). A 'Mysore' é uma cultivar de porte alto e com frutos externamente semelhantes aos frutos da 'Maçã', embora com sabor diferente. É muito produtiva, embora apresente o vírus BSV, patógeno que provoca uma redução no tamanho do cacho e no crescimento da planta (Cordeiro, 1999; Silva \& Alves, 1999).

As cultivares do tipo Prata são responsáveis por aproximadamente $60 \%$ da área cultivada com bananeira no Brasil. Apresentam normalmente porte alto e frutos de sabor doce a suavemente ácido, à exceção da 'Prata-Anã' ('Enxerto'), mutante da 'Branca' (Lichtemberg et al., 1998), que possui porte de médio a alto. Contudo, seus frutos possuem tamanho e sabor idênticos ao tamanho e ao sabor dos frutos da 'Prata'. A 'Pacovan'é mais rústica e mais alta do que a 'Prata' e apresenta frutos $40 \%$ maiores, com quinas que permanecem mesmo após a maturação. Sob irrigação, a sua produtividade supera em quase $100 \%$ a produtividade da 'Prata'. Os frutos das cultivares do subgrupo Terra são consumidos cozidos ou fritos, enquanto as cultivares do subgrupo Cavendish apresentam frutos doces mais consumidos no Sudeste e no Sul do Brasil e usados para exportação.

Todas as cultivares descritas são suscetíveis à sigatoka-amarela, à exceção da 'Maçã', da 'Mysore' e dos plátanos, à sigatoka-negra, à exceção da 'Mysore', e ao Moko (Silva \& Alves, 1999). As pragas e as doenças da cultura acarretam severas perdas na produção, as quais, sob certas circunstâncias, atingem até $100 \%$, pois, muitas vezes, não há uma alternativa eficiente de controle.

Uma das estratégias para a solução dos problemas mencionados é a criação de novas variedades resistentes a doenças, nematóides e pragas, mediante o melhoramento genético que possibilita a obtenção de híbridos superiores. A etapa final do processo consiste na avaliação dos genótipos em áreas de produção (Silva et al., 1998; Silva, 2000). As características analisadas em trabalhos de tal natureza são: ciclo da cultura, altura da planta, peso do cacho, número de frutos e comprimento do fruto (Alves, 1990; Ledo et al., 1997; Silva \& Alves, 1999).
O trabalho objetivou avaliar cultivares e híbridos de bananeira, visando à identificação de genótipos superiores que possam ser recomendados aos agricultores.

\section{Material e Métodos}

O trabalho foi realizado entre 1995 e 1998, na Embrapa-Centro Nacional de Pesquisa de Mandioca e Fruticultura Tropical, no Município de Cruz das Almas, Recôncavo Baiano, situado a 12 $40^{\circ} 39^{\prime \prime}$ de latitude Sul e $39^{\circ} 6^{\prime 2} 22^{\prime \prime}$ de longitude Oeste e a $220 \mathrm{~m}$ de altitude. A região apresenta temperatura média anual de $24^{\circ} \mathrm{C}$, precipitação média anual de $1.200 \mathrm{~mm}$, concentrada entre maio e junho, e umidade relativa em torno de $80 \%$. O clima é do tipo $\mathrm{Cl}$ (seco e subúmido), segundo a classificação de Thornthwaite. O solo da área experimental é o Latossolo Amarelo, textura média a argilosa, declive de 0\% a 3\% (Embrapa, 1993). Utilizou-se a irrigação por microaspersão, empregando-se o manejo recomendado para a cultura (Alves \& Oliveira, 1999; Borges et al., 1999).

Os caracteres analisados foram: altura da planta (m), diâmetro do pseudocaule a $30 \mathrm{~cm}$ do solo $(\mathrm{cm})$, peso do cacho (kg), número de frutos por cacho, comprimento do fruto $(\mathrm{cm})$ e ciclo. $O$ delineamento experimental foi o inteiramente casualizado, com 15 tratamentos e 18 repetições de uma planta de cada tratamento. Os genótipos avaliados em quatro ciclos foram as cultivares Pacovan, Prata-Comum, Prata-Anã, Thap Maeo, Mysore, Caipira, Nam, Grande-Naine e Nanica, e os híbridos PV03-44, PV03-76, Pioneira, PA03-22, FHIA-18 e JV03-15 (Tabela 1). O teste de comparação de médias foi o de Scott \& Knott. O espaçamento experimental foi de $4 \times 2 \times 2 \mathrm{~m}$.

\section{Resultados e Discussão}

Nas cultivares Grande-Naine e Nanica, o peso do cacho praticamente não se modificou no decorrer dos ciclos, enquanto na Pacovan, na Prata-Comum, na Mysore, na Prata-Anã e nos híbridos FHIA-18, PV03-44, PA03-22 e Pioneira, o caráter se estabilizou a partir do segundo ciclo (Tabela 2). No híbrido JV03-15, na 'Nam' e na 'Thap Maeo', houve uma tendência de elevação contínua até o quarto ciclo. No híbrido PV03-76, o peso do cacho se estabilizou no terceiro ciclo e, na 'Caipira', um decréscimo ocorreu a partir do segundo ciclo. Portanto, o primeiro ciclo não é o momento oportuno para analisar o peso do cacho na maioria dos genótipos, uma vez que o 
caráter pode apresentar variações no decorrer dos ciclos da cultura.

Na média dos quatro ciclos, a 'Thap Maeo' apresentou o maior peso do cacho, enquanto o híbrido FHIA-18 apresentou o segundo maior valor, superando sua genitora, a 'Prata-Anã' (Tabela 2). Com exceção apenas do JV03-15, os demais híbridos não superaram seus respectivos genitores, ou seja, tanto a Pioneira como o PA03-22 produziram menos que a 'Prata-Anã', como também o PV03-76 e o PV03-44 produziram menos que a 'Pacovan'. O JV03-15 foi mais produtivo que a 'Prata-Comum', genótipo de baixa produtividade e equivalente à genitora do híbrido abordado, a 'Prata-Java'.

O peso do cacho é um caráter que expressa a produtividade de um genótipo; no entanto, não pode ser considerado isoladamente na escolha de uma variedade, pois outros caracteres também influenciam o processo de seleção e a preferência do mercado consumidor, tais como os relacionados ao fruto (peso, comprimento, diâmetro, sabor e resistência ao despencamento). Assim, enquanto a 'Grande-Naine', pertencente ao subgrupo Cavendish e mais cultivada no Sul e no Sudeste do Brasil, é destinada à exportação, as variedades tipo Prata são preferidas em todas as demais regiões. Deve-se lembrar, ainda, que o sabor dos frutos dos híbridos nem sempre é idêntico ao sabor dos frutos dos seus respectivos genitores. Segundo Silva \& Alves (1999), os frutos do genótipo FHIA-18, híbrido da 'Prata-Anã', embo- ra muito saborosos, apresentam sabor um pouco diferente do dos frutos das variedades tipo Prata.

Trabalhos preliminares com híbridos demonstraram que tais genótipos podem apresentar boa produtividade, expressa principalmente pelo peso do cacho (Oliveira et al., 1993; Ledo et al., 1997). Embora o rendimento seja normalmente um caráter muito influenciado pelas condições ambientais, os resultados indicam que os híbridos avaliados oferecem uma boa perspectiva como alternativa às atuais variedades de bananeira, que são muito suscetíveis a diversas enfermidades.

O número de frutos por cacho apresentou, na maioria dos genótipos, uma tendência de crescimento contínuo ao longo dos ciclos, tais como na 'Prata-Comum', na 'Mysore', na 'Thap Maeo', na 'Nam', na 'Caipira' e nos híbridos PV03-44, PA03-22, JV03-15, FHIA-18 e Pioneira, culminando no mais alto valor no quarto ciclo (Tabela 2). Entretanto, o caráter decresceu do primeiro para o segundo ciclo, no híbrido FHIA-18, e do segundo para o terceiro, na 'Caipira', embora tivesse apresentado, nos genótipos mencionados, tendência de ascensão contínua até o quarto ciclo. Na 'Pacovan', na 'Prata-Anã' e no híbrido PV03-76, o número de frutos pareceu estabilizar-se no terceiro ciclo, ao passo que, na 'Grande-Naine' e na 'Nanica', praticamente não se verificaram alterações. Portanto, o primeiro ciclo também não deve ser considerado conclusivo para analisar o desempenho dos genótipos quanto ao número de frutos.

Tabela 1. Descrição dos genótipos de bananeira avaliados. Cruz das Almas, BA, 1995-1998.

\begin{tabular}{llcl}
\hline Genótipo & Grupo & Subgrupo & Descrição \\
\hline Grande-Naine & AAA & Cavendish & Cultivar de porte médio a baixo \\
Nanica & AAA & Cavendish & Cultivar de porte baixo \\
Caipira & AAA & - & Cultivar de porte médio a alto \\
Nam & AAA & - & Cultivar de porte médio a alto \\
Prata-Comum & AAB & Prata & Cultivar de porte alto \\
Pacovan & AAB & - & Cultivar mutante da Prata, de porte alto \\
Prata-Anã & AAB & - & Cultivar com frutos tipo prata \\
Mysore & AAB & - & Cultivar de porte médio a alto \\
Thap Maeo & AAB & - & Cultivar idêntica à Mysore \\
FHIA-18 & AAAB & - & Híbrido da Prata-Anã introduzido da FHIA ${ }^{(1)}$ \\
Pioneira & AAAB & - & Híbrido (Prata-Anã x Lidi) \\
PA03-22 & AAAB & - & Híbrido (Prata-Anã x Calcuttá) \\
PV03-44 & AAAB & - & Híbrido (Pacovan x Calcuttá) \\
PV03-76 & AAAB & - & Híbrido (Prata-de-Java x Calcuttá) \\
JV03-15 & AAAB & & \\
\hline
\end{tabular}

${ }^{(1)}$ Fundación Hondureña de Investigación Agrícola (Honduras, América Central). 


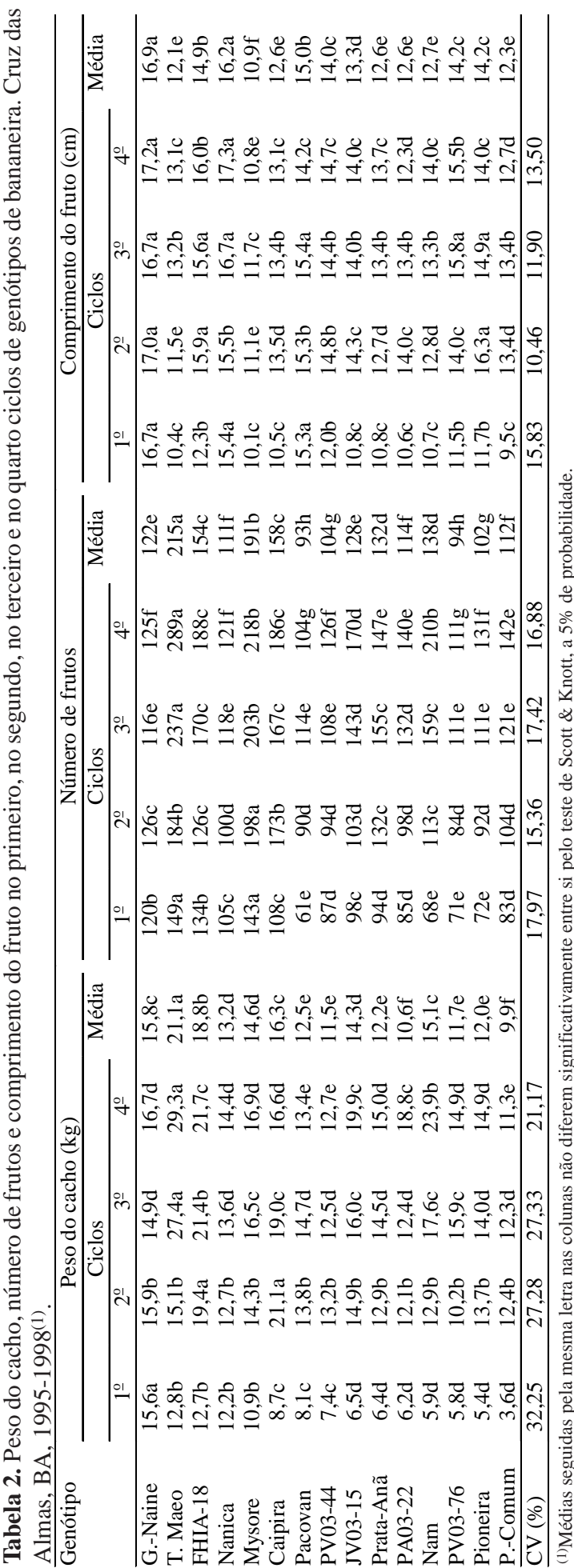

A 'Thap Maeo' e a 'Mysore' foram, no decorrer dos quatro ciclos, os genótipos que apresentaram o melhor rendimento do número de frutos por cacho (Tabela 2). O híbrido FHIA-18 obteve também um bom desempenho médio, superando sua genitora, a 'Prata-Anã', ao passo que os demais híbridos da referida cultivar, o PA03-22 e a Pioneira, não apresentaram desempenho equivalente no decorrer dos quatro ciclos. O híbrido PV03-44 superou, mesmo que de forma discreta, sua genitora, a 'Pacovan', enquanto o outro híbrido da referida cultivar, o PV03-76, foi equivalente à sua genitora. O híbrido JV03-15 foi levemente superior à 'Prata-Comum', genótipo equivalente à genitora do híbrido mencionado, a 'Prata-Java.'

O número de frutos é fundamental na determinação do tamanho e do peso do cacho (Silva et al., 1999b), revelando relevância no melhoramento genético da bananeira. Segundo Jaramillo (1982), o caráter está estreitamente relacionado ao número de pencas. Silva et al. (2000), em dois ciclos, confirmaram o bom rendimento no número de frutos dos híbridos FHIA-18 e PV03-44.

$\mathrm{Na}$ 'Pacovan', na 'Mysore' e na 'Grande-Naine', o comprimento do fruto não apresentou variações significativas entre os ciclos, mas, na 'Caipira', na 'Prata-Comum' e também nos híbridos JV03-15, PV03-44 e FHIA-18, o caráter se estabilizou no segundo ciclo e, na 'Thap Maeo', na 'Prata-Anã' e no híbrido PV03-76, no terceiro (Tabela 2). O caráter apresentou acréscimos contínuos na 'Nam' e na 'Nanica', ao longo dos ciclos, ou um valor mais elevado no segundo ciclo sucedido por um progressivo decréscimo até o quarto, como nos híbridos Pioneira e PA03-22.

Nos quatro ciclos, as maiores médias gerais do comprimento do fruto foram apresentadas pela 'Grande-Naine' e pela 'Nanica' (Tabela 2). A 'Pacovan' e ohíbridoFHIA-18 vieram em seguida. Dos três híbridos da 'Prata-Anã' (FHIA-18, Pioneira ePA03-22), apenas os dois primeiros a superaram, com médias gerais superiores à média geral da referida cultivar, enquanto o último (PA03-22) foi equivalente, ou seja, apresentou a mesma média geral. O híbrido JV03-15 também superou a 'Prata-Comum' genótipo similar à 'Prata-Java', genitora do híbrido abordado - ao longo dos quatro ciclos. A 'Thap Maeo' superou em aproximadamente $10 \%$ a 'Mysore'. Oliveira et al. (1993) e Silva et al. (2000) 
constataram resultados promissores, em relação ao comprimento do fruto, nos híbridos avaliados no presente trabalho.

$\mathrm{Na}$ 'Prata-Anã', na 'Caipira' e na 'Nanica', a altura da planta se estabilizou no segundo ciclo (Tabela 3). O primeiro ciclo não é o momento apropriado para analisar o porte, pois a estabilidade só é atingida posteriormente (Belalcázar Carvajal, 1991; Soto Ballestero, 1992; Alves \& Oliveira, 1999). O maior incremento na altura ocorre do primeiro para o segundo ciclo (Alves et al., 1984); todavia, os avanços tecnológicos referentes à densidade de plantio permitiram considerar a cultura como anual, devendose considerar o porte no primeiro ciclo (Belalcázar Carvajal, 1991).

Na média dos quatro ciclos, a 'Prata-Comum' apresentou a maior altura, enquanto a 'Nanica' revelou a menor (Tabela 3). Nenhum híbrido da 'Prata-Anã' (FHIA-18, Pioneira e PA03-22) foi estatisticamente mais alto que a cultivar genitora, assim como os híbridos PV03-76 e PV03-44 não superaram significativamente a 'Pacovan'. O híbrido JV03-15 foi menor que a 'Prata-Comum', genótipo análogo à 'Prata-Java', genitora do híbrido citado. Os híbridos Pioneira, JV03-15 e PA03-22 foram os menores genótipos tipo 'Prata', ratificando Oliveira et al. (1993).

A altura da planta é um caráter muito importante no melhoramento da cultura, e influi na densidade de plantio, no manejo (principalmente no escoramento e na colheita) e, conseqüentemente, na produção (Belalcázar Carvajal, 1991; Alves \& Oliveira, 1999).

Em relação ao diâmetro do pseudocaule, praticamente não houve variação, na 'Grande-Naine' e na 'Nanica', entre os ciclos avaliados (Tabela 3). $\mathrm{Na}$ 'Caipira', o caráter se estabilizou no segundo ciclo, e, na 'Pacovan', na 'Mysore' e no híbrido PV03-76, no terceiro. Nos demais genótipos, a média do caráter se elevou continuamente até o quarto ciclo, embora a taxa de crescimento verificada tenha diminuído a partir do terceiro ciclo.

As maiores médias do diâmetro do pseudocaule, no final dos quatro ciclos, foram obtidas pela 'Prata-Anã', pela 'Prata-Comum' e pelos híbridos JV03-15, PV03-76, PV03-44 e FHIA-18 (Tabela 3). Apenas os híbridos da 'Pacovan' (PV03-76 e PV03-44) superaram de forma significativa a variedade genitora no caráter abordado.

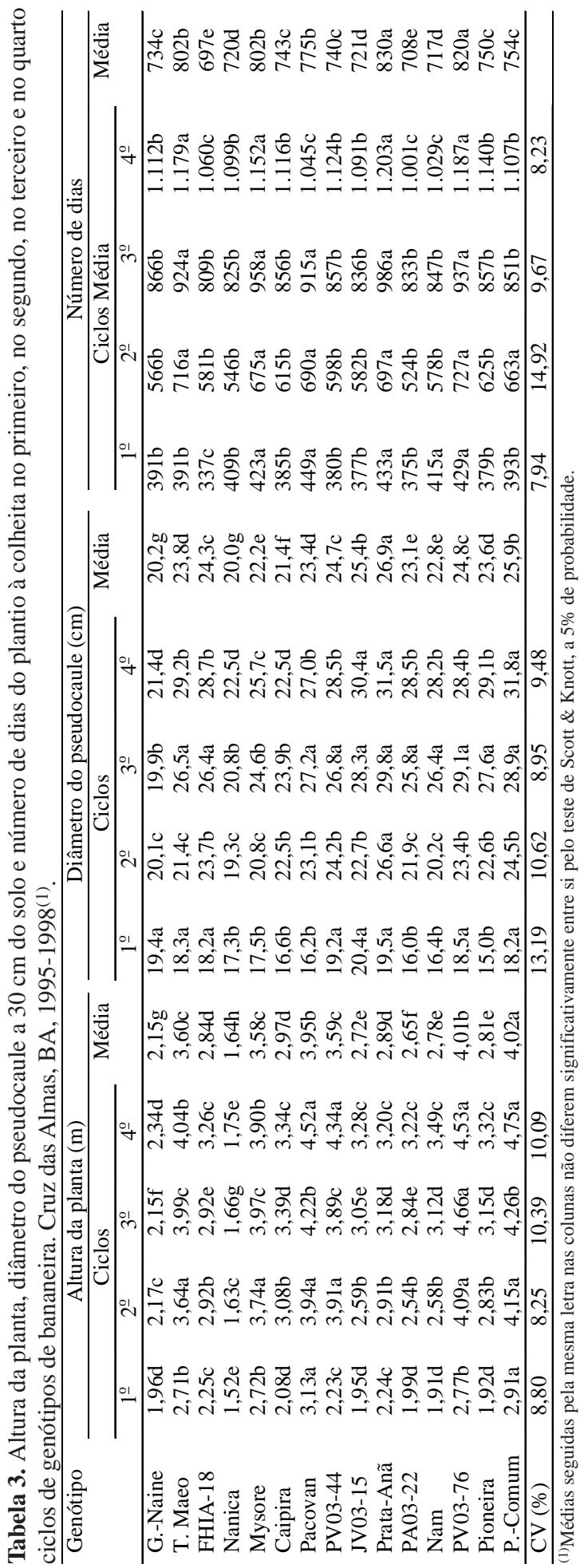

Pesq. agropec. bras., Brasília, v. 37, n. 11, p. 1567-1574, nov. 2002 
O diâmetro do pseudocaule é importante no melhoramento genético da bananeira, pois está relacionado ao vigor, e reflete a capacidade de sustentação do cacho. Os genótipos que apresentam um maior diâmetro do pseudocaule são menos suscetíveis ao tombamento (Silva et al., 1999a).

O híbrido FHIA-18 destacou-se no primeiro ciclo em relação ao número de dias do plantio à colheita (Tabela 3). Nos três ciclos seguintes, o referido híbrido também mostrou bom desempenho no caráter, integrando o grupo dos genótipos mais precoces. No segundo e no terceiro ciclo, os híbridos Pioneira, PV03-44, JV03-15 e PA03-22 igualmente se destacaram, já que se posicionaram entre os genótipos que proporcionaram a colheita em um intervalo menor. No quarto ciclo, a precocidade do híbrido PA03-22 foi similar à do híbrido FHIA-18.

Na média dos ciclos, quase todos os híbridos foram mais precoces que suas variedades genitoras (Tabela 3). Os três híbridos da 'Prata-Anã' (FHIA-18, PA03-22 e Pioneira) e o híbrido PV03-44, da 'Pacovan', superaram suas genitoras em precocidade, assim como o híbrido JV03-15 em relação à 'Prata-Comum', genótipo análogo à 'Prata-Java', genitora do híbrido mencionado. A única exceção foi o híbrido PV03-76, mais tardio que a 'Pacovan', sua genitora.

O ciclo é um caráter de relevância no melhoramento genético da bananeira, já que reflete a precocidade da planta. A redução do número de dias necessários à emissão do cacho é desejada, pois representa a antecipação do retorno do investimento aplicado na lavoura (Pereira, 1997).

Embora apenas um dos três híbridos avaliados da 'Prata-Anã' (FHIA-18) tenha sido superior em produtividade à referida genitora, alguns outros caracteres, além da precocidade, credenciam os outros dois híbridos (Pioneira e PA03-22) como genótipos que apresentam potencial para cultivo comercial. O híbrido Pioneira, apesar de ter sido menos produtivo que a 'Prata-Anã', é mais resistente a alguns isolados do agente etiológico da sigatoka-amarela do que a referida cultivar, o que lhe possibilitaria apresentar uma produtividade superior em locais demasiadamente infestados, como em áreas úmidas (Cordeiro \& Kimati, 1999; Cordeiro et al., 1999). O híbrido PA03-22 apresentou mais resistên- cia à sigatoka-amarela do que sua cultivar genitora (Daniells, 2000). A resistência à referida doença confere aos dois híbridos abordados a mesma vantagem em relação à 'Prata-Anã'. O híbrido FHIA-18, além da superioridade na produtividade, também apresentou, em relação à genitora, uma maior resistência à sigatoka-amarela (Cordeiro \& Kimati, 1999; Cordeiro et al., 1999) e à sigatoka-negra (Daniells, 2000).

Entre os híbridos FHIA-18, PA03-22 e Pioneira, os dois primeiros apresentam um nível de resistência ao mal-do-panamá superior ao da 'Prata-Anã' (Cordeiro et al., 1993; Daniells, 2000). Assim, os três híbridos possuem potencial para ser lançados como cultivares, a depender dos requisitos e das exigências tanto das áreas de produção como dos mercados consumidores, notadamente o sabor do fruto, cuja preferência pode implicar no êxito ou no fracasso do genótipo. Apesar de muitas características desejáveis, o híbrido FHIA-18 apresenta frutos que, embora saborosos, são um pouco diferentes dos frutos do tipo Prata (Silva \& Alves, 1999).

Os híbridos da 'Pacovan' (PV03-76 e PV03-44) apresentaram uma produtividade similar àquela da referida genitora, mas revelaram um maior vigor, caráter expresso pelo diâmetro do pseudocaule. O híbrido PV03-44, além de vantagens na precocidade e no porte, apresenta uma maior resistência à sigatoka-amarela e ao mal-do-panamá, propiciando-lhe um melhor desempenho em áreas contaminadas (Cordeiro et al., 1993, 1999; Cordeiro \& Kimati, 1999).

O híbrido JV03-15, quando comparado à 'Prata-Comum', genótipo semelhante a sua genitora, a 'Prata-Java', demonstrou maior peso do cacho, maior número de frutos, maior comprimento do fruto, menor porte e maior precocidade. Na robustez, expressa pelo diâmetro do pseudocaule, o referido híbrido foi estatisticamente equivalente à 'Prata-Comum', apresentando porém uma maior resistência à sigatoka-amarela, o que lhe proporcionaria uma vantagem ainda maior sobre a referida cultivar, suscetível ao patógeno responsável (Cordeiro \& Kimati, 1999; Cordeiro et al., 1999). Como seus frutos são muito saborosos (Silva \& Alves, 1999), conclui-se que o genótipo possui potencial para tornar-se uma variedade. Contudo, quanto ao grau de suscetibilidade ao mal-do-panamá, não difere da 'Prata-Comum' (Cordeiro et al., 1993). 
A 'Thap Maeo' e a 'Mysore' não diferiram no porte e na precocidade; no entanto, a 'Thap Maeo' excedeu a 'Mysore' na produtividade, expressa pelos caracteres peso do cacho, número de frutos e comprimento do fruto, e no vigor, expresso pelo diâmetro do pseudocaule. Considerando-se que os frutos das duas cultivares apresentam as mesmas características físicas e o mesmo sabor, pode-se inferir que a 'Thap Maeo' poderá substituir a 'Mysore', cujas folhas exibem os sintomas do vírus-das-estriasda-bananeira (BSV) (Silva, 2000).

\section{Conclusões}

1. A 'Thap Maeo' pode substituir a 'Mysore' em razão de seu vigor e de seu melhor desempenho nos caracteres que expressam a produtividade.

2. Todos os híbridos avaliados apresentam vantagens em relação aos respectivos genitores, reunindo, assim, potencial para recomendação futura aos agricultores.

\section{Referências}

ALVES, E. J. Principais cultivares de banana no Brasil. Revista Brasileira de Fruticultura, Cruz das Almas, v. 12, n. 3, p. 45-61, jan. 1990.

ALVES, E. J.; OLIVEIRA, M. de A. Práticas culturais. In: ALVES, E. J. (Org.). A cultura da banana: aspectos técnicos, socioeconômicos e agroindustriais. 2. ed. rev. Brasília: Embrapa-SPI /Embrapa-CNPMF, 1999. p. 335-352.

ALVES, E. J.; SHEPHERD, K.; MESQUITA, A. L. M.; CORDEIRO, Z. J. M. Caracterização e avaliação de germoplasma de banana (Musa spp.). In: CONGRESSO BRASILEIRO DE FRUTICULTURA, 7., 1984, Florianópolis. Anais... Florianópolis: Sociedade Brasileira de Fruticultura/Empasc, 1984. p. 202-212.

BELALCÁZAR CARVAJAL, S. L. El cultivo del plátano en el trópico. Cali: Feriva, 1991. 376 p.

BORGES, A. L.; OLIVEIRA, A. M. G.; SOUZA, L. S. Solos, nutrição e adubação. In: ALVES, E. J. (Org.). A cultura da banana: aspectos técnicos, socioeconômicos e agroindustriais. 2. ed. rev. Brasília: Embrapa-SPI/ Embrapa-CNPMF, 1999. p. 197-260.

CORDEIRO, Z. J. M. Doenças. In: ALVES, E. J. (Org.). A cultura da banana: aspectos técnicos, socioeconômicos e agroindustriais. 2. ed. rev. Brasília: Embrapa-SPI/ Embrapa-CNPMF, 1999. p. 353-407.

CORDEIRO, Z. J. M.; KIMATI, H. Avaliação da resistência de genótipos de bananeira à sigatoka-amarela em condições naturais de infecção. Revista Brasileira de Fruticultura, Jaboticabal, v. 21, n. 3, p. 243-246, dez. 1999.

CORDEIRO, Z. J. M.; KIMATI, H.; DIAS, C. T. S. Resistência de genótipos de bananeira ao mal-de-sigatoka. Summa Phytopathologica, Jaboticabal, v. 25, n. 4 , p. 318-324, out./dez. 1999.

CORDEIRO, Z. J. M.; SHEPHERD, K.; SOARES FILHO, W. dos S.; DANTAS, J. L. L. Avaliação de resistência ao mal-do-panamá em híbridos tetraplóides de bananeira. Fitopatologia Brasileira, Brasília, v. 18, n. 4, p. 478-483, dez. 1993.

DANIELLS, J. Which banana variety should I grow? Infomusa, Montpellier, v. 9, n. 1, p. 31-33, June 2000.

EMBRAPA. Serviço Nacional de Levantamento e Conservação de Solos (Rio de Janeiro, RJ). Levantamento detalhado dos solos do Centro Nacional de Pesquisa de Mandioca e Fruticultura Tropical. Cruz das Almas: Embrapa-CNPMF, 1993. 126 p. (Boletim de Pesquisa, 7).

FAO (Roma, Itália). FAO statistical databases: agricultural production: crops primary: Brazil: bananas. Disponível em: http://apps.fao.org/page/collections. Acesso em: 6 fev. 2002.

JARAMILLO, R. C. Las principales características morfológicas del fruto de banano, variedad Cavendish gigante (Musa AAA) en Costa Rica. Panamá: UpebImpretex, 1982. $42 \mathrm{p}$.

LEDO, A. S.; SILVA, S. O.; AZEVEDO, F. F. Avaliação preliminar de genótipos de banana (Musa spp.) em Rio Branco (AC). Revista Brasileira de Fruticultura, Cruz das Almas, v. 19, n. 1, p. 51-56, abr. 1997.

LICHTEMBERG, L. A.; MIRANDA, M.; MALBURG, J. L.; SACKNIES, R. G.; PEIXOTO, A. N. Situação da bananicultura na região Sul do Brasil. In: SIMPÓSIO BRASILEIRO SOBRE BANANICULTURA, 4., 1998, Campo Grande. Anais... Jaboticabal: Funep, 1998. p. 66-96.

OLIVEIRA, M. de A.; ALVES, E. J.; SHEPHERD, K.; SOARES FILHO, W. dos S.; CORDEIRO, Z. J. M.; DANTAS, J. L. L.; SILVA, S. de O. e. Avaliação agronômica de cultivares e híbridos promissores de banana I: porte médio. Revista Brasileira de Fruticultura, Cruz das Almas, v. 15, n. 3, p. 7-13, dez. 1993. 
PEREIRA, M. C. T. Crescimento e produção de primeiro ciclo da bananeira (Musa spp.) 'Prata-Anã' (AAB) em sete espaçamentos, em Jaíba e Visconde do Rio Branco (MG). 1997. 56 f. Dissertação (Mestrado em Fitotecnia) - Universidade Federal de Viçosa, Viçosa.

SILVA, S. de O. e. Melhoramento genético da bananeira. In: SIMPÓSIO BRASILEIRO DE MELHORAMENTO DE FRUTEIRAS, 2., 2000, Viçosa. Anais... Viçosa, MG: UFV, 2000. p. 21-48.

SILVA, S. de O. e; ALVES, E. J. Melhoramento genético e novas cultivares de banana. Informe Agropecuário, Belo Horizonte, v. 20, n. 196, p. 91-96, jan./fev. 1999.

SILVA, S. de O. e; ALVES, E. J.; SHEPHERD, K.; DANTAS, J. L. L. Cultivares. In: ALVES, E. J. (Org.). A cultura da banana: aspectos técnicos, socioeconômicos e agroindustriais. 2. ed. rev. Brasília: Embrapa-SPI/ Embrapa-CNPMF, 1999a. p. 85-105.
SILVA, S. de O. e; CARVALHO, P. C. L.; SHEPHERD, K.; ALVES, E. J.; OLIVEIRA, C. A. P.; CARVALHO, J. A. B. S. Catálogo de germoplasma de bananeira (Musa spp.). Cruz das Almas: Embrapa-CNPMF, 1999b. 152 p. (Documentos, 90).

SILVA, S. de O. e; MATOS, A. P.; ALVES, E. J. Melhoramento genético da bananeira. Pesquisa Agropecuária Brasileira, Brasília, v. 33, n. 5, p. 693-703, maio 1998.

SILVA, S. de O. e; ROCHA, S. A.; ALVES, E. J.; CREDICO, M.; PASSOS, A. R. Caracterização morfológica e avaliação de cultivares e híbridos de bananeira. Revista Brasileira de Fruticultura, Jaboticabal, v. 22, n. 2, p. 161-169, ago. 2000.

SOTO BALLESTERO, M. Bananos: cultivo y comercialización. 2. ed. San José: Litografía e Imprenta Lil, 1992. $674 \mathrm{p}$. 